\title{
ARQUEOLOGÍA APLICADA AL DESARROLLO DE COMUNIDADES ATACAMEÑAS
}

\author{
ARCHAEOLOGY APPLIED TO THE DEVELOPMENT OF \\ ATACAMEÑO COMMUNITIES
}

\author{
Ángel Bravo González*
}

\begin{abstract}
Desde el año 1996, en la comuna de San Pedro de Atacama, se ha estado trabajando con las comunidades indígenas de Coyo y Quitor para poner en valor, proteger y administrar dos importantes sitios arqueológicos: Aldea de Tulor y Pukara de Quitor, pertenecientes a su rico patrimonio cultural. Ambos proyectos han sido financiados por la CONADI de Calama, y han tenido el auspicio de las propias comunidades. El ideario de tales proyectos se basa en la intrínseca capacidad que poseen las comunidades de administrar su propio patrimonio; para ello se les ha capacitado en administración y finanzas y en la formación de guías expertos en los sitios arqueológicos. La ejecución de ambos proyectos ha tenido trabas de orden burocrático por lo que en el presente trabajo se quieren discutir y reflexionar al respecto.
\end{abstract}

Palabras claves: San Pedro de Atacama, patrimonio cultural, administración de sitios arqueológicos, comunidades indígenas.

I have been working in the native communities of Coyo and Quitor, since the year 1996, it is located in the community of San Pedro de Atacama, Province of El Loa in northern Chile (Second Region). I have worked here in order to value, protect and manage two important archaeological sites called: The Tulor Village and the Quitor Fortress, which belong to this worthy cultural patrimony. Both projects have been financed by CONADI in Calama, and the projects have been sponsored by the communities themselves. The main idea of these projects is based on the intrinsically capacity the communities have to manage their own patrimony. For this, they have been trained in management and financial subjects and expert guides in the sites have been also prepared. The performance of both projects has had some obstacles, which are discussed here.

Key words: San Pedro de Atacama, cultural heritage, management of archaeological sites, indigenous communities.

Es preciso poseer no sólo lo que los hombres han pensado y sentido. Sino lo que sus manos han manejado, lo que su fuerza ha ejecutado, lo que sus ojos han contemplado todos los días de su vida.

(Ruskin 1987).

El presente trabajo tiene los siguientes objetivos. En primer lugar, compartir mi experiencia como arqueólogo en el desarrollo de la actividad turística en San Pedro de Atacama y de dos comunidades atacameñas emblemáticas; las comunidades indígenas de Coyo y de Quitor, pues ambas cuentan dentro de sus territorios con dos importantes yacimientos arqueológicos (aldea de Tulor y Pukara de Quitor), la primera, una de las más antiguas del Período Formativo o Neolítico y el segundo, el sitio monumental más importante de todo el patrimonio cultural atacameño. Deseo, además, compartir mis reflexiones sobre el uso y el valor, en el presente, del patrimonio histórico de los atacameños.

Intento delinear una aproximación a la práctica arqueológica que sale del ámbito universitario y académico, para ser más asequible a las comunidades y al público en general, que en calidad de turistas visitan nuestro entorno. En otras palabras, utilizar el conocimiento del pasado de una forma hasta ahora no tradicional para el mundo arqueológico.

Finalmente, se busca analizar el marco jurídico en el que se insertan las actividades de la arqueología, en particular, y de las ciencias sociales, en general.

\section{En Busca de Nuestros Sueños}

Al comienzo de la década de los años 90 San Pedro de Atacama y sus alrededores participaban -desde a lo menos 15 años atrás- de un creciente

* Municipalidad de San Pedro de Atacama. 
circuito turístico internacional que traía a estas tierras un significativo número de "buscadores de paz y de paisajes indómitos". Los lugares preferidos eran los majestuosos y sempiternos rincones puneños y el "patrimonio cultural viviente" que conforma la etnia atacameña, herederos del riquísimo pasado de la Cultura San Pedro de Atacama (ca. años 400 a.C. a 1.450 d.C.).

Evidentemente las comunidades altoandinas no manejaban todavía este "negocio" y no imaginaban siquiera lo que se les venía. De una u otra forma el patrimonio histórico, arqueológico y antropológico estaba en riesgo creciente de destrucción e intervención incontrolada, ya que había altas expectativas económicas hacia esta "industria sin chimeneas", que otorga significativos dividendos a través de los impuestos cobrados a las numerosas empresas turísticas que se han instalado en San Pedro de Atacama. Como cientistas sociales ya levantábamos nuestras voces, alertando sobre el peligro inminente de esta actividad (Bravo 1996,1999$)$. Nuestra primera tarea, desde dentro de esta floreciente industria turística, fue proteger y conservar los recursos, apelando a las conciencias de los tour operadores y atendiendo personalmente a los turistas como "incipientes guías de turismo" (en el presente estamos en la categoría de guías culturales).

El mundo académico nos abría sus puertas, pues se inauguraba el Liceo Likán Antai, exclusivamente para los hijos de esta tierra de cada rincón y pueblo de la inmensidad atacameña, se iniciaba así la reconversión del desarraigo, mediante la entrega de una educación de calidad y equidad para todos. De esta forma pudimos "poner en valor" el riquísimo patrimonio cultural atacameño, principalmente a través de la asignatura "Patrimonio Cultural". Por aquellos años (1997) se realizaba un congreso de arqueología en la ciudad de Copiapó y enviamos un trabajo titulado "Arqueología en el aula". Hasta el presente aún no sabemos por qué fue rechazado; la respuesta tentativa que poseemos es que un antiguo paradigma de investigación imperaba aún en las aulas universitarias. El título del trabajo se inspiraba en nuestra práctica habitual de traspasar el críptico lenguaje que emplean los arqueólogos a los jóvenes escolares atacameños. Surgían así los primeros y auténticos guías locales, que pasaban a integrar ilustradamente el "patrimonio cultural viviente" como denomina el amauta peruano Carlos Milla Villena, a los actuales descendientes de culturas altoandinas que con- tinúan vivos y haciéndose cargo de su propio patrimonio arqueológico (Milla Villena 1983:270).

Corría el año 1996 y los bienes patrimoniales sufrían ante la avasalladora venida de turistas de todos los rincones del mundo; se sumaba a ellos un grueso contingente de chilenos caracterizados por su escaso interés en el patrimonio cultural, que desde el verano de 1994 había irrumpido en San Pedro de Atacama, haciendo de este un punto obligado cada verano y cada invierno. Todo este escenario hacía urgente la necesidad de proteger los sitios arqueológicos, especialmente aquellos más próximos al pueblo, que a través de la creciente difusión en los mass media eran vulnerables a la demanda por cultura y por el ahora bien económico denominado "pasado atacameño". Los habitantes de los diferentes pueblos sólo contemplaban este repentino auge de su tierra y su cultura.

La oficina de la Corporación de Desarrollo Indígena (CONADI) en Calama a través de su jefa, la señorita Liliana Cortés, consciente de la urgencia de conservar el patrimonio arqueológico atacameño en riesgo, llamó a licitación pública para presentar proyectos de esa índole. Nosotros conformamos un grupo multidisciplinario y con el apoyo de la comunidad indígena de Coyo nos embarcamos en una experiencia novedosa y sin parangón en Chile, pero que, en el extranjero, fundamentalmente en Europa, Estados Unidos, Medio Oriente, México y Perú, ya llevaba un par de décadas de práctica. Así, yendo en contra de la práctica arqueológica tradicional y de algunas instituciones públicas, que no creían en la autogestión de las propias comunidades sobre su patrimonio, logramos sacar adelante el primer proyecto de Desarrollo Indígena en Bienes Culturales. Este proyecto tuvo por objetivo proteger y conservar el sitio arqueológico de Tulor, creando un parque arqueológico, administrado por la propia comunidad de Coyo. La puesta en valor de este sitio se realizó a través de la construcción de una pasarela y un mirador, para así evitar el ingreso del público a los diferentes recintos. Además, se capacitaron guías locales para que fueran expertos en el sitio, con información arqueológica actualizada, y a la comunidad para administrar eficientemente, no sólo en gestión, sino también en contabilidad, para convertir el parque en un negocio rentable en el tiempo. De este proyecto se informó a todos los tour operadores, se les invitó a reuniones informativas y se les involucró activamente. Hoy en día el Parque Arqueológico de Tulor es un modelo a seguir 
por las comunidades atacameñas; es más, el Director Regional de Corporación Nacional Forestal (CONAF) de aquel entonces nos comunicó que avalaría cualquier proyecto de este tipo, pues estaba convencido de su éxito.

El próximo paso en esta senda fue la obtención del segundo proyecto apoyado por la comunidad, esta vez fue la Comunidad Indígena de Quitor, la idea se denominó "Puesta en valor del sitio Pukara de Quitor, para su Conservación y Posterior Administración y Gestión Arqueológico-Turística". La CONADI de Calama avalaba una vez más a las comunidades atacameñas. Lamentablemente desde 1997, año en que nos adjudicamos el proyecto, hasta la fecha aún estamos entrampados con la conclusión del mismo y el Pukara de Quitor continúa destruyéndose año tras año con la visita de turistas, los que alcanzan unas 40.000 personas, tal como se desprende de la propuesta técnica contenida en el proyecto mencionado. Dicho proyecto, al igual que el de Tulor, considera todas las variables para hacerlo sustentable en el tiempo. Debemos consignar que de todos los sitios arqueológicos de la provincia El Loa que están en el circuito turístico, este es el de mayor viabilidad económica, pues se encuentra muy próximo a San Pedro de Atacama, por tanto recibe la mayor carga de turistas.

Paralelamente, un equipo multidisciplinario, liderado por Ana María Barón, que participó en los proyectos antes descritos, elaboró un proyecto mayor denominado "Catastro de Sitios Arqueológicos de la Provincia El Loa" que, con la misma idea de fondo, pretende que todas las comunidades atacameñas de esta provincia administren, gestionen y conserven su patrimonio histórico y arqueológico. Esta idea también fue financiada por la CONADI de Calama. La novedad de este proyecto es que contó con el auspicio de la Universidad José Santos Ossa.

En el inicio del siglo XXI esta idea está siendo gradualmente acogida y varios son los proyectos que tienen a las comunidades locales e indígenas como sus protagonistas (Ayala et al. en este volumen; Fernández; Lima en este volumen; Nielsen et al. en este volumen). Creemos firmemente que nuestro trabajo integra eficazmente conservación, turismo y comunidades, permitiendo que estas últimas gestionen y autosustenten proyectos de gran envergadura para su desarrollo futuro, dentro de una economía cada vez más globalizada.
Hasta ahora nos hemos involucrado con entusiasmo en la capacitación arqueológica y económica de las comunidades, no sólo en las instancias mencionadas, sino también junto a iniciativas de importantes hoteles y agencias de viaje de capitales chilenos en San Pedro de Atacama. Al mismo tiempo hemos asesorado diferentes proyectos que conjugan las palabras cultura y turismo.

Conscientes de la creciente necesidad de los turistas de conocer con veracidad la cultura y medio ambiente que visitan, poseemos un programa de exposiciones y charlas sobre la Cultura San Pedro y su entorno; además se ha publicado un pequeño libro que ha ayudado especialmente a los guías de San Pedro a informar con objetividad a sus clientes (Bravo 1999).

Finalmente, hacemos un alcance sobre un gran problema que ha traído el turismo: cualquiera puede trabajar como guía turístico en San Pedro de Atacama, sin siquiera poseer la instrucción básica para realizar esa labor profesional. Al respecto, son muchas las anécdotas que han surgido, ya que los guías por querer congraciarse con los turistas inventan cualquier cosa, engrosando de esta forma los muchos mitos que ya circulan sobre el los antecedentes del patrimonio. En este aspecto a la arqueología le cabe un rol importante en el futuro, tal como veremos en el siguiente tópico de nuestro trabajo.

\section{Reflexiones del Uso del Pasado Atacameño en la Actualidad}

La economía moderna ha convertido los bienes producto del esfuerzo humano en mercancía. Una mercancía es cualquier género objeto de comercio. También los bienes culturales han sido transformados en género de comercio a partir del momento en que se les ha adjudicado un determinado valor convertible en moneda y ha aparecido gente dispuesta a pagar por ellos (Ballart 1997:223).

Leyendo lo anterior no nos cabe duda de cuál debe ser el uso que especialmente en San Pedro de Atacama y en toda la provincia El Loa debemos dar al pasado de las comunidades atacameñas. Ya señalábamos en el punto anterior que el turismo ha sido una actividad creciente desde la década de los 
ochenta. También indicamos que uno de los graves problemas que presenta el turismo ligado a la cultura es la desinformación y la ausencia de una planificación adecuada. Después de más de 20 años de turismo, aún podemos afirmar que la industria está en pañales. Aunque la oferta hotelera es amplia, desde un hotel cinco estrellas hasta numerosos camping, y ha crecido el número de tour operadores y agencias, la información patrimonial, más que avanzar ha retrocedido. Con perplejidad vemos cómo cada temporada se integran guías bilingües, que por el sólo hecho de hablar otra lengua que no es la nativa se convierten en expertos guías de la zona. Lógicamente las aberraciones van y vienen, se hacen intentos para mejorar la situación, recurriendo a obras de divulgación científica en el área antropológica y arqueológica; pero, como dijimos, el lenguaje utilizado en dichos textos conspira en contra de los resultados y como si se tratara de otra lengua las interpretaciones abundan por doquier. Lo peor ocurre cuando se visitan los lugares culturales ya que allí la desinformación se hace más patente. Hay una frase que han acuñado los propios guías en torno a los tour arqueológicos, ellos dicen que realizan un "tour mentirológico". Este jocoso neologismo expresa por sí mismo lo que hemos venido diciendo.

Cabe aquí una simple pregunta: ¿Qué rol deberían ocupar los arqueólogos en esta lamentable situación? Intentaremos dar respuesta a la pregunta.

El legado material de las sociedades del pasado es la materia prima para el trabajo de arqueólogos, historiadores y museólogos, entre otros profesionales. Si este legado material se encuentra en zonas geográficas con remanentes de poblaciones originales: ¿Cuál debería ser el rol social de los arqueólogos especialmente? Nos parece que es aquí donde los arqueólogos están llamados a dar un aporte sustantivo dentro de su labor profesional, pues son ellos quienes trabajan con esa materia prima y la "recrean", por tanto su misión natural es entregarla al gran público con simplicidad y rigor científico: la práctica arqueológica está en el pasado para el pasado y en el uso de ese pasado aquí en el presente.

Siguiendo con el uso del pasado. En nuestras tierras atacameñas vemos como inexorablemente el patrimonio cultural sigue sufriendo en muchos rincones por el abandono del Estado y por la ignorancia de los hombres. Pese a tener una legislación "moderna" en materia de patrimonio cultural, es doloroso ver como día a día ese patrimonio se es- fuma ante nuestros ojos, aquí por el desarrollo, allá por el saqueo y los turistas. Lamentablemente si queremos que esta industria cultural permanezca debemos sacarnos de la cabeza que son bienes renovables. Nuevamente el papel que puedan cumplir las comunidades es vital.

Ante este lamentable espectáculo, vemos con optimismo como son los propios turistas, en especial los que concurren en busca de "la ilusión del pasado" quienes dan voces de alerta al respecto. Este público no es como cualquier otro, generalmente son personas con formación universitaria y que en sus lugares de origen ocupan influyentes puestos, y ellos precisamente se han dado cuenta de la urgencia por conservar. Más de alguno esta ligado con instituciones e investigadores y ellos han comenzado a abrir las conciencias, preparando el terreno a lo que viene.

Es así cómo bajo la triada de conservación, estudio y difusión, el patrimonio histórico ha visto nacer, en Europa especialmente, iniciativas loables que conjugan el turismo y la cultura, ha sido Francia e Inglaterra quienes nos han demostrado como el uso del pasado puede estar inserto dentro de políticas estatales y privadas que ayuden a levantar la autoestima de las comunidades y en especial contribuir al progreso ético, material y cívico de los ciudadanos. Si en este país copiamos todo lo que viene desde afuera, sería bueno imitar estos ejemplos, especialmente ahora que el terreno es fértil: el pasado puede servir al presente de varias formas (ideológicas, agrícolas, constructivas o médicas). Los arqueólogos podrán hacer cosas peores que acentuar los beneficios prácticos de su disciplina, ayudando de ese modo a justificar sus demandas de financiación pública y privada. Sin embargo, quedará poca arqueología a la que se puedan dedicar las futuras generaciones, a no ser que se detenga la enorme destrucción de nuestro patrimonio y se introduzcan medidas de conservación adecuadas (Collin y Bahm 1998:494).

Finalmente podemos afirmar que San Pedro de Atacama posee una consolidada difusión y re- 
cepción mundial, además se está trabajando en los temas de protección y la valorización. Entonces, el trabajo futuro debe ser mejorar el conocimiento, la interpretación y la difusión de ideas, para así estar seguros que el uso que se le está dando al pasado es el mejor posible, hecho que además no sólo lo agradecerán las comunidades actuales, sino también sus descendientes.

\section{En Busca de una Aplicación de la Arqueología Fuera del Ámbito Académico}

El título de este trabajo no resulta antojadizo, por cuanto en el presente la arqueología debe trascender las esferas netamente universitarias o académicas y cumplir un rol social decisivo así como cualquier otra disciplina. Claro está que por años, especialmente en tiempos de la dictadura militar, el ámbito de aplicación de la arqueología se restringió a la práctica dentro de las aulas universitarias y de los museos, y evidentemente en los congresos de la especialidad que eran las instancias en que los arqueólogos compartían su trabajo. Y ese, desde siempre ha sido el escenario natural de la práctica arqueológica. No obstante, en el presente, con una democracia más o menos madura, el rol que le cabe a la arqueología y a los arqueólogos ya no puede ser solamente ese. Principalmente en aquellos lugares que, como San Pedro de Atacama, poseen poblaciones originarias que exigen conocer su pasado, como forma de entender el presente y proyectarse al futuro. Esta que es una frase cliché dentro de las Ciencias Históricas, no lo es aquí, ya que como hemos visto las comunidades atacameñas, cada vez con mayor fuerza, se están haciendo cargo de su pasado para mostrarlo con orgullo a los turistas que cada año visitan su tierra.

Nuevamente una pregunta: ¿Cuál debe ser el rol de la arqueología en la actualidad ante este panorama? Obviamente el acento no sólo debe estar en la teoría o en la metodología que nuestra disciplina utiliza, que por lo demás no son privativas de la arqueología. La atención, por añadidura debe estar en la práctica arqueológica. Se ha reconocido que la arqueología -mejor dicho su producto: el pasado- es usada para distintos fines, por ejemplo el Estado de Israel la utiliza como una forma de subrayar su continuidad histórica y, por tanto, de justificar su existencia (Collin y Bahm1998:494). Si esto es así, ¿podría en la zona atacameña usarse de forma similar?
Ya hemos dicho también, que otro uso del producto arqueológico es el conocimiento adquirido a través de un método y una técnica especial. Es hora ya de llegar al público en general, en este caso los turistas, a través de la preparación de guías informados. No hablamos sólo de esporádicos cursos, sino de una práctica habitual. Esto tiene antecedentes en esta zona, tales como las iniciativas de la Universidad de Antofagasta (2000), y nuestra propia práctica, en que nos hemos acercado a las comunidades y al público y no al revés. Al parecer, el Museo Arqueológico R. P. Gustavo Le Paige, dependiente de la Universidad Católica del Norte, va a iniciar esfuerzos en esta línea (Francisco Téllez, comunicación personal, año 2001).

Un buen ejemplo de Arqueología Aplicada lo encontramos en la zona del Lago Titicaca donde un equipo multidisciplinario de arqueólogos e ingenieros agrónomos ha "revivido" los campos de cultivo en altura (denominados camellones) e integrado a las comunidades con éxito (Erickson 1986), demostrando que las antiguas tecnologías son eficaces. Nosotros, con alumnos del liceo, pertenecientes a comunidades altoandinas e ingenieros agrónomos queremos continuar en esa senda.

Finalmente, creemos que dos son los elementos que la práctica arqueológica debería afianzar en el futuro en la zona atacameña con urgencia, por un lado:

Proporcionar a la gente en general una mejor comprensión del pasado humano. Por lo tanto, se requiere una hábil popularización (en exposiciones, libros y programas de televisión de yacimientos y museos), pero no todos los arqueólogos están preparados para dedicar a esto tiempo y pocos son capaces de hacerlo bien (Collin y Bahm 1998:507).

Y por otro, la conservación arqueológica, en los cuales:

hay dos niveles principales (...). El primero es la recogida de información de forma que se puedan reconocer y registrar adecuadamente los yacimientos y zonas pertinentes. El segundo es la conservación de aquellos yacimientos y zonas que puedan ser protegidos de un modo eficaz (Collin y Bahm 1998:494). 
Pensamos que en Chile la conservación no ha sido efectiva, sólo está en el espíritu de la ley, como veremos en el siguiente tema; falta darle el cuerpo necesario. El concepto de conservación general del patrimonio atacameño debe inevitablemente estar asociado al desarrollo de las comunidades; ya hemos dado ejemplos de lo anterior. En Europa ha aparecido con fuerza la Arqueología Industrial, perfectamente aquí podríamos hablar de la Arqueología Aplicada (al desarrollo de comunidades atacameñas).

\section{¿Las Leyes Protegen Efectivamente el Patrimonio Cultural Atacameño?}

Existen, a lo menos, cinco cuerpos legales de la nación, que en el espíritu velan por la conservación del patrimonio cultural: Ley $\mathrm{N}^{\circ} 17.288$ de 1970, sobre Monumentos Nacionales; Ley No 19.175 del 20 de marzo de 1993, Orgánica Constitucional Sobre Gobierno y Administración Regional; Ley $\mathrm{N}^{\circ} 19.253$ del 05 de octubre de 1993, Ley Indígena; Ley $\mathrm{N}^{\circ} 19.300$ de 1996, Sobre Bases del Medio Ambiente; Ley No 18.695 del 11 de enero de 2000, texto refundido de La Ley Orgánica Constitucional de Municipalidades.

En el caso de la Ley 17.288, tal como su nombre lo indica se refiere en extenso a los monumentos nacionales, entre los que se encuentra, naturalmente el patrimonio histórico, arqueológico y antropológico. También explica cómo deben ser tratados dichos monumentos y las acciones que las personas e instituciones interesadas en el área deben realizar.

La Ley 19.175, en sus artículos 2, 4, 14, 17, 19 y 20 , se refiere a las acciones tanto de los funcionarios de gobierno como las que éstos deben seguir para resguardar adecuadamente el patrimonio. Por otra parte, la Ley 19.253 naturalmente habla del patrimonio indígena en todo el texto, pero especialmente en el artículo 28 y en el 29, donde -a la vez- se hace mención de las Leyes 17.288 y 19.175, buscando la armonía entre todas las instancias dedicadas al tema que nos ocupa. En este sentido se hace mención especial a la CONADI y el papel que debe desempeñar en el cuidado del patrimonio arqueológico, histórico y cultural, en el artículo 39.

Con respecto a la Ley de Bases del Medio Ambiente conviene recordar que es un complemen- to esencial a las demás leyes, por cuanto el desarrollo natural de un país necesariamente se topa con los intereses de las comunidades, en especial con el patrimonio cultural.

Finalmente, también la Ley de Municipalidades otorga atención al cuidado del patrimonio en el artículo 5 y especialmente en los artículos 6 y 7 donde menciona los instrumentos de desarrollo entre los que se cuentan el plan de desarrollo comunal y el plan regulador, elementos esenciales en el progreso cultural de la comuna.

Con todas estas leyes, ¿cómo es posible que aún el patrimonio cultural siga sin la adecuada protección y conservación? ¿Qué está pasando con las políticas estatales que aún no logran un equilibrio entre desarrollo y patrimonio de las comunidades? Sin duda algunas respuestas se expresaron en el Encuentro y en los trabajos publicados en este volumen.

\section{Conclusiones}

No es pretensión de este trabajo responder a todas las interrogantes planteadas, ni mucho menos agotar los distintos temas; simplemente pretendemos poner una voz de alerta ante cuestiones que nos parecen esenciales a nuestro trabajo en una zona tan delicada con el tema del patrimonio cultural.

Todas estas reflexiones han ido surgiendo a lo largo de casi diez años de práctica arqueológica ligada al desarrollo de las comunidades atacameñas y al turismo. Durante este tiempo y en la inmensidad de los magníficos paisajes circundantes hemos ido conformando un cúmulo de experiencias que tocan con dos realidades que hace un tiempo parecían aisladas, pero que hoy son una realidad inquietante que urge de respuestas. Las preguntas ya son muchas y necesitan ser contestadas a la brevedad si es que realmente queremos nuestra profesión y sobre todo si queremos que nuestra disciplina tenga una plena inserción en la realidad social presente. Ya mucho hemos obtenido de estas comunidades, es la hora de devolverles la mano para que sigan confiando en nosotros. Hoy por hoy, para los cientistas sociales la confianza de las comunidades en la utilidad de sus trabajos es un bien cada vez más escaso.

Confiados estamos que en este Encuentro hemos llegado, tras dos días de trabajo y debate, a acuerdos perdurables que beneficiarán a todas las partes involucradas. 
Agradecimientos: Especialmente a las Comunidades de Coyo y de Quitor. Al señor Saúl Cervantes, funcionario del Museo Arqueológico R. P. Gustavo Le Paige. A la Ilustre Municipalidad de San Pedro de Atacama. A los turistas que alguna vez he atendido. A mi familia: Claudia, Sebastián y Constanza. A la tierra de los Likan Antai. A mi querido liceo. Al equipo que ha laborado codo a codo en esta empresa.

\section{Referencias Citadas}

Ballart, J.

1997 El Patrimonio Histórico y Arqueológico, Valor y Uso. Ariel Patrimonio Histórico, Barcelona.

Barón, A. M.

1999 Arqueología y Patrimonio Cultural. Santiago.

Bravo, A.

1990 Hacia una Antropología Aplicada: Diagnóstico de una Realidad Industrial. Santiago.

1996 Diagnóstico de una Realidad Educacional de la Puna de la II Región (El caso atacameño). Ministerio de Educación, Santiago.

1999 Atacama: Donde el Hombre se Reencuentra con su Ser. Síntesis de Divulgación Científica, San Pedro de Atacama. Collin, R. y P. Bahm

1998 Arqueología: Teoría, Métodos y Práctica. Editorial Akal, Madrid.
Erickson, C.

1986 Agricultura en camellones en la cuenca del Lago Titicaca: Aspectos técnicos y su futuro. En Andenes y Camellones en el Perú Andino, editado por C. de la Torre y M. Burga, pp. 331-350. Consejo Nacional de Ciencia y Tecnología, Lima.

Milla, C.

1992 Génesis de la Cultura Andina, Colegio de Arquitectos del Perú, Lima.

Ruskin, J.

1987 Las Siete Lámparas de la Arquitectura. Traducido por Manuel Crespo y Purificación Mayoral. Editorial Stylos, Barcelona. 
